Steiner, Henry J., dan Alston, Philip. 1996. International Human Rights in Context (Law, Politics, and Morals). Oxford: Clarendon Press

Suharsimi Arikunto. 2002. Prosedur Penelitian Suatu Pendekatan Praktek. Jakarta: PT Rineka Cipta

Undang-undang No 22 tahun 2007 tentang Penyelenggara Pemilihan Umum

Undang-Undang No. 10 tahun 2008 tentang Pemilihan Umum

Undang-Undang No. 2 tahun 1998 tentang Partai Politik

Universal Declaration of Human Rights (Deklarasi Universal Hak Asasi Manusia), diambil dari Modul Training HAM untuk Polisi PBHI Yogyakarta, tahun 2006

\section{PENGARUH PENGASUHAN DAN PENGETAHUAN ORANGTUA TENTANG NAPZA TERHADAP PERILAKU RELAPSE ANAK}

\author{
Oleh: \\ Sri Weni Utami, Hetti Rahmawati, \& \\ Rias Gesang Kinanti \\ Universitas Negeri Malang
}

\begin{abstract}
Abstrak
Peran orangtua penting dalam menanggulangi penyalahgunaan NAPZA remaja dan upaya pencegahan kekambuhan (relapse prevention) karena orangtua adalah subsistem sentral pengendali sebuah keluarga dengan anak-anak di dalamnya. Sehingga orangtua memerlukan kesempatan belajar ketrampilan dalam hal mengurangi risiko perilaku relapse anak. Parent Support Training sebagai salah satu alternatif edukasi bagi orangtua remaja penyalahguna NAPZA untuk belajar dan berlatih tentang: pengetahuan tentang NAPZA, adiksi, pencegahan perilaku relapse dan dimensi pengasuhan efektif serta belajar rencana tindakan.

Untuk mencapai tujuan tersebut dilakukan survei awal penjajakan untuk menguji pengaruh pola pengasuhan orangtua (variabel bebas) dan pengetahuan orangtua tentang NAPZA (variabel bebas) terhadap perilaku relapse anak kembali menyalahounakan NAPZA (sebagai variabel tergantung). Metode pengambilan data dengan metode angket, analisis data angket dengan analisis regresi. Data tambahan diperoleh dari analisis kebutuhan pelatihan parent support training tentang urgensi pelatihan, karakteristik, bahan dan strategi pelatihan dengan metode wawancara. Analisis deskriptif digunakan untuk mengolah hasil survei. Subjek penelitian terdiri dari 60 orangtua dari remaja penyalahguna NAPZA yang berada di kota Malang, Yogyakarta dan Bogor.

Hasil analisis regresi menyatakan bahwa ada hubungan negatif yang signifikan antara pola asuh orangtua dengan perilaku relapse anak ( $p$ value $<0,05$ ), pengetahuan orangtua tentang NAPZA tidak berpengaruh terhadap perilaku relapse subjek (p-value $>0,05$ ), secara bersama variabel pola asuh orangtua dan pengetahuan orangtua tentang NAPZA memberikan kontribusi sebesar 30,10\% terhadap perilaku relapse anak $\left(R^{2}\right.$
\end{abstract}


=0,301; p-value < 0,000). Sumbangan sebesar 69,99\% dijelaskan oleh faktor-faktor selain kedua variabel bebas tersebut. Hasil survei menunjukkan bahwa sebanyak 60\% menghendaki pelatihan mencegah kekambuhan/preventing relapse, 40\% coping masalah anak, dan bahan pelatihan sebaiknya memberi pemahaman tentang dimensi pengasuhan, NAPZA, adiksi dan pencegahan kekambuhan. Penelitian ini menunjukkan peran penting pola pengasuhan orangtua dalam pencegahan perilaku relapse anak. Maka perlu pengembangan model parent support training untuk peningkatan ketrampilan pengasuhan efektif bagi orangtua yang memiliki anak recovering addict. Pengembangan media pembelajaran termasuk modul, panduan dan buku bacaan dengan mempertimbangkan hasil survei ini.

Keywords: parent support training, pola pengasuhan orangtua, NAPZA, perilaku relapse

\section{PENDAHULUAN}

Penyalahgunaan NAPZA (Narkotika, Alkohol, Psikotropika dan Zat Adiktif lainnya) pada remaja dapat dipengaruhi oleh beberapa faktor, salah satunya adalah lemahnya hubungan dalam lingkungan keluarga. Pengasuhan orangtua dan monitoring disiplin yang tidak efektif, komunikasi yang miskin juga menjadikan munculnya masalah penggunaan obat dalam beberapa budaya (Allison, dkk., 1990 ; Nichols \& Schwartz, 2004). Faktor-faktor risiko dalam keluarga memberikan kemungkinan munculnya perilaku penyalahgunaan NAPZA karena menjadi sumber kerentanan remaja untuk mencoba melarikan diri dari masalah dengan menyalahgunakan NAPZA (Wills dkk, 2000).

Proses intervensi selama ini yang dilakukan pusat rehabilitasi NAPZA pada orangtua residen adalah dengan melaksanakan family support group. Agenda yang digulirkan biasanya tergantung pada apa yang ingin disampaikan oleh orangtua dan tidak terencana sebelumnya. Alternatif lain yang dapat dilakukan untuk mengoptimalkan forum ini adalah memberikan pembekalan pada orangtua dengan ketrampilan

\section{Gesang Kinanti)}

pengasuhan sehingga akan melengkapi intervensi komunitas, tidak hanya ditujukan pada remaja residen saja. Prediksi kesembuhan tidak selalu terpenuhi, maka perlu bantuan dari orangtua, keluarga dan lingkungan dalam menciptakan situasi kondusif bagi remaja recovering addict untuk beradaptasi dengan perilaku bebas NAPZA.

Hubungan atau keterikatan emosional antara orangtua dengan anaknya adalah anugerah alami yang dimiliki setiap orangtua dalam mengasuh dan membesarkan anak-anak mereka. Proses belajar dan berlatih adalah sarana dalam mengelola sumber kekuatan ikatan emosional tersebut ke dalam kehidupan praktis keluarga. Orangtua secara alamiah telah melakukan tugas dan fungsi pengasuhan anak sejak peran sebagai orangtua dimulai, namun demikian tetap diperlukan pembekalan dalam khasanah pengasuhan anak remaja. Hal ini menjadi pertimbangan bagi orangtua dengan anak remaja penyalahguna NAPZA yang tengah menjalani terapi di pusat rehabilitasi NAPZA atau remaja yang sudah kembali ke rumah selepas menjalani terapi. Lingkungan primer keluarga perlu disiapkan lebih kondusif bagi penyalahguna NAPZA terutama setelah mereka pulang dari perawatan di tempat rehabilitasi (Sholevar \& Schwoeri, 2003).

Gaya pengasuhan orangtua adalah kecenderungan perlakuan-perlakuan orangtua terhadap anak dalam proses interaksi dengan anak dalam rangka melaksanakan peran pengasuhan (Hauser dkk., 1984), juga disebut sebagai kecenderungankecenderungan orangtua dalam berinteraksi dengan anak. Gaya pengasuhan dibedakan dalam gaya enabling (mendukung) dan gaya constraining (menghambat) yang keduanya memiliki komponen kognitif dan afektif. Dukungan orangtua, sikap memaafkan orangtua dan jalinan hubungan yang lebih hangat dan nyaman dengan anak juga anggota keluarga lain perlu dipersiapkan agar anak tidak merasa diabaikan dan terbina hubungan baru yang 
suportif dalam mencegah kekambuhan anak menyalahgunakan NAPZA kembali (Westermeyer, 1997).

Keterlibatan orangtua dalam hal ini dapat dimulai dengan melihat kembali bagaimana persepsi orangtua terhadap penyalahgunaan NAPZA, partisipasinya terhadap kesuksesan program penanggulangan penyalahgunaan NAPZA, terutama bagaimana kemampuan untuk bekerja bersama dengan pihak lain yang relevan. Beberapa penelitian yang menekankan keterlibatan orangtua dalam pelatihan yang bertujuan meningkatkan ketrampilan parenting telah menunjukkan adanya hubungan pada keberhasilan intervensi berbasis keluarga dalam menghadapi masalah penyalahgunaan NAPZA pada anak remaja (Szapocznick, dkk., 1988 ; Liddle \& Dakof, 1995). Intervensi pada orangtua yang memiliki anak bermasalah seperti Parent Management Training terbukti menurunkan stres orangtua dan meningkatkan interaksi lebih baik orangtua-anak, sehingga faktor risiko perilaku relapse anak dapat diminimalisir (Kazdin \& Whitley, 2003). Pesan yang dikembangkan dalam keluarga untuk tidak saling menyalahkan sebagai elemen utama strategic structural system engangement dari Szapoznick, dkk. (1988) dengan jalan memahamkan keluarga dalam menghadapi ketergantungan NAPZA anak, menguatkan sistem dan ikatan keluarga.

Pengetahuan orangtua tentang NAPZA adalah seberapa orangtua memahami: pengertian, contoh dan jenisnya, faktor penyebab dan penghambat penyalahgunaan, pengenalan tanda penyalahgunaan NAPZA pada remaja (Hawari, 2006). Pengetahuan orangtua dan pemahaman atas gejala adiksi dan relapse akan membantu orangtua dalam mencegah kembali lagi munculnya perilaku adiksi NAPZA pada anak. Pertanyaan yang dalam penelitian ini adalah: apakah pola pengasuhan dan pengetahuan tentang NAPZA orangtua memiliki pengaruh dalam menurunkan kecenderungan relapse anak?
Tujuan penelitian ini adalah untuk mengidentifikasi faktorfaktor yang berhubungan dengan perilaku relapse / kambuh penyalahguna NAPZA, yaitu pengasuhan orangtua dan pengetahuan NAPZA orangtua, serta mengidentifikasi kebutuhan dan isi program yang dibutuhkan dalam rangka merancang model Parent Support Training bagi orangtua yang memiliki anak penyalahguna NAPZA.

\section{CARA PENELITIAN}

Penelitian kuantitatif ini untuk menguji pengaruh pola pengasuhan orangtua (variabel bebas) dan pengetahuan orangtua tentang NAPZA (variabel bebas) terhadap perilaku relapse anak kembali menyalahgunakan NAPZA (sebagai variabel tergantung). Instrumen untuk mengukur variabel pengasuhan orangtua berupa angket Pengasuhan Orangtua, yang dikembangkan berdasarkan dimensi pengasuhan Hauser, dkk. (1984), variabel pengetahuan orangtua tentang NAPZA diukur dengan angket Pengetahuan NAPZA berdasarkan Hawari (2006) dan perilaku relapse anak menurut persepsi orangtua diukur dengan angket Perilaku Relapse berdasarkan Somar (2001). Subjek penelitian yang terdiri dari 60 orangtua dari remaja penyalahguna NAPZA yang berada di kota Malang, Yogyakarta dan Bogor. Subjek penelitian diputuskan berdasarkan teknik non random (purposive sampling).

Metode pengumpulan data dengan metode angket, analisis data angket dengan analisis regresi. Data tambahan lain diperoleh dari analisis kebutuhan pelatihan parent support training tentang urgensi pelatihan, karakteristik, bahan dan strategi pelatihan dengan metode wawancara. Analisis deskriptif digunakan untuk mengolah hasil survei. 


\section{PEMBAHASAN}

Dari hasil analisis regresi menunjukkan bahwa variabel pola pengasuhan orangtua dan pengetahuan orangtua tentang NAPZA memberikan kontribusi sebesar $30,10 \%$ terhadap perilaku relapse anak $\left(R^{2}=0,301\right)$. Sumbangan sebesar $69,99 \%$ dijelaskan oleh faktor lain diluar kedua variabel bebas tersebut. Hasil lain menunjukkan kedua variabel bebas, yaitu variabel pengetahuan orangtua tentang NAPZA dengan variabel pengasuhan orangtua, jika bekerja bersama merupakan prediktor yang berpengaruh secara signifikan pada variabel perilaku relapse anak (nilai $F=13,699 ; p$ value $<0,000)$.

Ada hubungan negatif yang signifikan antara pola pengasuhan dan perilaku relapse anak $(\beta=-5,102 ; p$-value $<0,05)$, atau pola pengasuhan berpengaruh negatif secara signifikan pada perilaku relapse anak. Artinya bahwa semakin meningkat pola pengasuhan enabling (mendukung anak) yang dilakukan orangtua, maka semakin menurun kecenderungan perilaku relapse anak untuk kembali menyalahgunakan NAPZA, demikian sebaliknya. Hasil lain menunjukkan tidak ada hubungan antara variabel pengetahuan orangtua tentang NAPZA dengan perilaku relapse anak $(\beta=-0,55 ; \quad p$-value $=0,620 ; \quad p$-value $>0,05)$. Maka pengetahuan orangtua tentang NAPZA tidak berpengaruh secara signifikan terhadap perilaku relapse anak. Artinya, semakin bertambah pengetahuan orangtua tentang NAPZA tidak berpengaruh terhadap menurunnya kemungkinan perilaku relapse anak kembali menyalahgunakan NAPZA, demikian sebaliknya.

Hasil penelitian menunjukkan peran pola pengasuhan dari orangtua, sebagai prediktor mencegah kekambuhan anak. Orangtua masih memerlukan program kegiatan untuk mengasuh anak lebih baik. Penelitian ini mendukung alasan dilakukan pelatihan ketrampilan bagi orangtua dalam memahami dan belajar pengasuhan yang tangguh dan efektif dalam mendampingi putra putri mereka yang terkena NAPZA.
Temuan di atas menunjukkan bahwa pola pengasuhan orangtua perlu diperhatikan sebagai faktor potensial yang mendukung keberhasilan orangtua dalam mencegah perilaku relapse/kekambuhan anak dibandingkan variabel pengetahuan orangtua tentang NAPZA.

Harapan orangtua dari wawancara yang dilaksanakan bersama nara sumber orangtua penyalahguna NAPZA sebelumnya, menunjukkan bahwa orangtua perlu membekali dirinya dengan program kegiatan positif bersama orangtua lain dalam pelatihan bagi orangtua berisiko tinggi, dalam hal ini orangtua yang memiliki anak remaja penyalahguna NAPZA. Sehingga transfer of learning selama pelatihan dapat diterapkan dalam kehidupan sehari hari untuk memiliki kekuatan mencegah anaknya kembali menyalahgunakan NAPZA (relapse). Somar (2001) melihat pencegahan kekambuhan (relapse) dan interaksi orangtua dan anak adalah ketrampilan yang harus dimiliki orangtua dalam berhubungan dengan anak mereka yang penyalahguna NAPZA, agar orangtua menjadi sumber dukungan bagi pemulihan anak. Ini sesuai dengan yang dikemukakan oleh Todd (1988), bahwa orangtua adalah agen perubah lewat komunikasi yang tidak saling menyalahkan, jujur, saling membantu dalam interaksi keluarga.

Dimensi pengasuhan dalam care (kasih), control (kontrol), dan communication (komunikasi) seperti yang dikemukakan oleh McGillicuddy, dkk. (2001), khususnya dalam hubungan atau interaksi orangtua dengan anak remajanya juga tergali selama wawancara dan diskusi kelompok terarah. Care (kasih) adalah intimacy atau kedekatan fisik dan emosional, perlakuan orangtua yang peduli dengan kebutuhan fisik dan emosional anak. Control (kontrol) adalah penerapan aturan dan tujuan tegas dalam mengendalikan perilaku. Communication (komunikasi) adalah tindakan komunikatif, adanya umpan balik tentang tingkah laku yang harus dipahami dan dimengerti diantara orangtua, anak, pengambilan keputusan dan aktivitas bersama keluarga. 
Survei ini menunjukkan bahwa urgensi dilakukannya program parent support training bagi orangtua yang memiliki anak penyalahguna NAPZA, terutama fokus pada belajar dan berlatih pengasuhan efektif. Berdasarkan hasil survei analisis kebutuhan tentang materi pelatihan menunjukkan bahwa orangtua lebih memilih topik tentang pencegahan kekambuhan dan belajar ketrampilan pengasuhan efektif sebagai materi penting yang perlu ada jika pelatihan dilaksanakan. Panduan berupa buku bacaan, modul pelatihan bagi pelatih profesional adalah komponen penting yang terekam dalam identifikasi sehingga materi ini harus dirancang dan dipersiapkan secara matang sebelum model parent support training ini dikembangkan dan diuji lebih lanjut.

\section{SIMPULAN}

1. Ada hubungan negatif yang signifikan antara pola asuh orangtua dengan perilaku relapse anak ( $p$-value $<0,05)$.

2. Pengetahuan orangtua tentang NAPZA tidak berpengaruh terhadap perilaku relapse subjek ( $p$-value $>0,05$ ).

3. Secara bersama variabel pola asuh orangtua dan pengetahuan orangtua tentang NAPZA memberikan kontribusi sebesar $30,10 \%$ terhadap perilaku relapse anak $(\mathrm{R} 2=0,301$; $\mathrm{p}$-value $<$ 0,000). Sumbangan sebesar 69,99\% dijelaskan oleh faktorfaktor selain kedua variabel bebas tersebut.

4. Sebanyak $60 \%$ menghendaki pelatihan mencegah kekambuhan/ preventing relapse, $40 \%$ coping masalah anak, dan bahan pelatihan sebaiknya memberi pemahaman tentang dimensi pengasuhan, NAPZA, adiksi dan pencegahan kekambuhan.

5. Peran penting pola pengasuhan orangtua dalam pencegahan perilaku relapse anak sehingga perlu pengembangan model parent support training untuk peningkatan ketrampilan pengasuhan efektif bagi orangtua yang memiliki anak recovering addict.

\section{DAFTAR PUSTAKA}

Allison, K.; Leone, P.E.; \& Spero, E.R.1990. Drug and alcohol use among adolescents : social context and competence. Dalam Leone, P.E. (Ed.). Understanding Troubled and Troubling Youth. Newbury Park : Sage Publications.

Hauser, S.T., Powers, S.I., Noam, G.G. \& Jacobson, A.M. 1984. Familial contexts of adolescent ego development. Child Development, 55. 195-213.

Hawari, D. 2006. Penyalahgunaan dan Ketergantungan NAZA ( Narkotika, Alkohol \& Zat Adiktif). Edisi Kedua. Jakarta : Balai Penerbit FKUI.

Kazdin, A.E. \& Whitley, M.K. 2003. Treatment of parental stress to enhance therapeutic change among children referred for aggressive and antisocial behavior. Journal of Consulting and Clinical Psychology, 60. 733-747.

Liddle, H.A. \& Dakof, G.A. 1995. Efficacy of family therapy for drug abuse : promising but not definite. Journal of Marital Family Therapy, 21.511-543.

McGillicuddy, N.B., Rychtarik, R.G., Duquette, J.A.\& Morshheimer, E.T. 2001. Development of skill training program for parents of substance - abusing adolescents. Journal of Substance Abuse Treatment, 20. 59-68.

Nichols, M. P. \& Schwartz, R.C. 2004. Family Therapy Concepts and Methods. 6 th ed. Boston : Pearson Education, Inc.

Sholevar, G.P. \& Schwoeri, L.D. 2003. Alcoholic and SubstanceAbusing Families. Dalam Sholevar, G.P. \& Schwoeri, L.D. (Eds.). Textbook of Family and Couples Therapy : Clinical Applications. Washington, DC : American Psychiatric Publishing, Inc. 
Somar, L. 2001. Kambuh, Relapse. Sudut pandang bagi mantan pecandu narkoba. Jakarta : Penerbit PT Gramedia Widiasarana bekerjasama dengan Yayasan Kasih Mulia.

Szapocznik, J., Perez-Vidal, A., Brickman, A., Foote, F., Santisteban, D., Hervis, O., \& Kurtines, W. 1988. Engaging adolescent drug abusers and their families into treatment : A strategic structure systems approach. Journal of Consulting \& Clinical Psychology, 56. 552-557.

Todd, T.C. 1988. Treating families with a chemically dependent member. Dalam Nunnaly , E.W., Chilman, C.S., \& Cox, F.M. (Eds.). Mental Illness, Delinquency, Addictions and Neglect : Families in Trouble Series. Vol. 4. Newbury Park: Sage Publications.

Westermeyer, J. 1997. Substance -related disorders. Dalam Ammerman, R.T \& Hersen, M. (Eds.). Handbook of Prevention and Treatment with Children and Adolescents : Intervention in The Real World Context. New York : John Wiley \& Sons, Inc.

Wills, T.A., Brody, G.H., Gibbons, F.X. , \& Gerrard, M. 2000. Protection and vulnerability processes relevant for early onset of substance use : a test among African American children. Health Psychology, 19. 253 - 263.

\section{MODEL PENILAIAN TRANSAKSI \\ PIHAK BERELASI YANG TERINDIKASI TUNNELING: BUKTI EMPIRIS PADA TRANSAKSI PIHAK \\ BERELASI DI INDONESIA}

Oleh:

Ratna Candra Sari

Universitas Negeri Yogyakarta

Email: chan_sari@yahoo.com

\begin{abstract}
This study focuses on the expropriation of non-controlling shareholders through tunneling activity. Current study in tunneling still found obstacles in measurement because it is difficult to prove, although tunneling activity going on in business practices. The objective of this is to develop tunneling valuation model. This study defines the tunneling as related party transactions that are used to tunnel out of public companies' resource for the benefit of the controlling shareholder. Tunneling in this study was divided based on the resources being tunneled that are cash flow tunneling and asset tunneling.

The formation a valuation model using data of disclosure of statements affiliate and conflict of interest transactions 20102011. Based on the assessment method of tunneling, the transaction is classified as cash flow tunneling as $40.5 \%$ and asset tunneling as 34\%. The company which announced related party transaction which indicated tunneling obtain negative abnormal return during the announcement of the related party transaction.
\end{abstract}

Keywords: tunneling, transaksi pihak berelasi 